\title{
A DISCUSSION ABOUT CULTURE AND INFORMATION SECURITY POLICY COMPLIANCE: A SUB-CULTURALLY BOUND DETERMINANT-REDEFINING THE HOFSTEDE HYPOTHESIS
}

\author{
Fahad A. Al-Khalifa, MS., Robert Morris University, faast100@mail.rmu.edu \\ Frederick G. Kohun, Ph.D., Robert Morris University, Pittsburgh, kohun@rmu.edu \\ Robert J. Skovira, Ph.D., Robert Morris University, Pittsburgh, skovira@rmu.edu
}

\begin{abstract}
While organizations have initiated knowledge management initiatives to systematically and methodically capture both explicit and tacit (or silent) knowledge, these initiatives have experienced mixed results. Inherent organizational idiosyncrasies have bounded the transferability and reusability of the knowledge base. Characteristics such as relevance, timeliness, but most important, cultural context, bind both the generalizable and transferable value of knowledge. For the knowledge to have value and utility, the cultural context must be taken into consideration. The problematic generalization and applicability of the Hofstede Hypothesis is redefined as a matter of statistical aggregation averages. The collectivity that establishes the essence of culture has many faces that situationally define the culture context (i.e. profession, organization, religion, and ethnicity). Application of the model to demographic, professional, organizational, and other identities may be more useful, telling and generalizable than contemporary national profiles. The framework is readily adaptable to identifiable more homogeneous sub-cultures, and hence a potential source of data that can validate the universality of the Hofstede Hypothesis to document multi-dimensional cultural profiles within the context of a national cultural environment. Thus, this paper addresses the cultural ground for non-compliance by Saudi citizens. In doing so, the paper explores the relation of culture to information security policies and practices. The paper argues that compliance and noncompliance is a consequence of a semantical construction of reality [13].
\end{abstract}

Keywords: Saudi Culture, Organizational Culture, Information Security, Policy

\section{INTRODUCTION}

Knowledge and knowledge management is contextualized and situational. While organizations have initiated knowledge management initiatives to systematically and methodically capture both explicit and tacit (or silent) knowledge, these initiatives have experienced mixed results. Inherent organizational idiosyncrasies have bounded the transferability and reusability of the knowledge base. Characteristics such as relevance, timeliness, but most important, cultural context, bind both the generalizable and transferable value of knowledge. For the knowledge to have value and utility, the cultural context must be taken into consideration.

Knowledge is defined as a "mix of framed experience, values, contextual information, and expert insight that provides a framework for evaluating and incorporating new experiences and formation... In organizations, it often becomes embedded not only in documents or repositories but also in organizational routines, processes, practices and Norms" [7]. Given that each organization, department, problem and problem is culturally bound, the knowledge associated with each situation can be argued to be appropriate only in similar cultural settings. It goes without saying that policies of information security are needed to define and maintain practices of information security. In today's world, organizations and governmental agencies have implemented and maintain information security practices based on policies formed in the context of the organizations and governmental agencies. This context for this paper is culture. Policies are explicit statements of values and objectives based on values by which specific practices are defined [23]. Policies are an aspect of the construction of an information security model depicting the possible actions and their consequences which are dependent in part upon psychological and social factors or conditions [4]. Policies and attending models form the ground by which organizations and governmental agencies ensure individuals' compliance to information security practices [6]. 
In Saudi Arabia, while organizations and governmental agencies are aware of the significance of information security policies [1], there appears to be a disconnect when the focus is on individuals' compliance with the policies or practices. There appears to be a lack of concern and carelessness toward information security. This disregard for the consequences of non-compliance with information security policies appears to be based in cultural meanings and values of the Saudi society.

Thus, this paper addresses the cultural ground for non-compliance by Saudi citizens. In doing so, the paper explores the relation of culture to information security policies and practices. The paper argues that compliance and noncompliance is a consequence of a semantical construction of reality [13].

This paper reviews the literature about the various factors affecting information security policies and compliance. It will focus on the relation of culture, a society's system of meanings, as a constructive factor not only for policy development and the creation of practices but for understanding compliance problems. Moreover, it develops a perspective on the relation of Saudi culture, beliefs and values, to personal compliance or non-compliance with information security policies and practices. Finally, the paper concludes with a cultural model for understanding how a society's meaning-system creates difficulties for agencies responsible for the enforcement of compliance with information security policies and practices.

\section{Hofstede Hypothesis Re-examined}

The work of Geert Hofstede has been discussed and debated over the past 30 years. Hofstede's notion of national culture is essentially based on five conceptions. He hypothesizes that culture displays a geographic or territorial uniqueness, is nationally shared from a statistical average vantage point, is inherently mentally subjective, is determinate as the influence, displays identifiable characteristics and predictable consequences, and is enduring [20]. Hofstede's dimensions of power distance, individualism, masculinity, uncertainty avoidance, and long term orientation (and most recently nurturing) together provide the basis of a profile that is reflective of a centered average of national cultural characteristics. Discussion, however, has emerged from numerous studies applying his data gathering questionnaire to the same national cultural entities as established by Hofstede in his initial worldwide study of IBM employees. Given the resulting cultural profiles are varied from the original Hofstede profiles; the resulting profiles are interesting through the pragmatism of providing an analytical tool to help explain cultural difference within a national context. The question becomes, what defines the national culture in what context? With the advent of readily accessible mass media, the internet, and varied social identity it can be argued that any individual may at eh same time harbor the profile of multiple identities within the context of national identity. One can ear many cultural hats. Beyond national identity there is ethnic identity, professional identity, organizational identity, social/sport/hobby identity, as well as religious identity [16]. Each of which manifests cultural attributes, values, language and practice that may contradict the cultural attributes of one or more of the other cultural identities an individual may assume. Individuals manifest the cultural attributes and characteristics of the culture they selfidentify with at any given point in time. Hence, in Hofstedian terms, each of the cultural dimensions would reflect the cultural identity assumed by an individual all within the realm of a particular national context.

The Hofstede perspective: "Culture is always a collective phenomenon ... Culture consists of the unwritten rules of the social game. It [culture] is the collective programming of the mind that distinguished the members of one group or category of people from others" [13]; see [11] for an early view; see also [15]. There are a couple of questionable aspects of the perspective defined above. This perspective is the source of what can be called the Hofstede Hypothesis. What are the questionable aspects? The first is the word and idea of "programming"; the second is the word and idea of "mind"; there is a possible additional aspect to be noted which is the term and idea "unwritten rules of the social game". What vocabulary or taxonomic domain is the source here? And, what ontological space affords an environment for these ideas?

Furthermore, does "programming" reference the ontological space of computer science or information science? So, programming is computing; thinking is computational. The model appropriate may be the information processing of mind. This may allow for a construal of the idea as a cognitive psychological affair. That is, reality is made, or computed, in terms of mental models [9] tacitly configuring situations, actions, consequences, and meanings.

Or, can "programming" as an idea be construed simply as a set of social habits, or practices? Practices as social schemes silently are in play bounding a group's members' activities. Analogous, perhaps, to a "program" of a social 
event which orders or organizes the social event as a situation of meaning; a sense-making document organizing people's experiences; a program of frames.

Does "mind" reference the ontological domain of cognitive psychology, wherein mind is construed as a set of operative mental models, cognitive schemas, or scripts? Or, should this idea be construed as a set of social practices or social habits [24]? Or, can "mind" be thought of as a set of "language games" representative of a "way of life" according to Wittgenstein?

Another aspect (the third) of a programmed mind is that some of the programming consists of "unwritten rules" of social behavior; the learning of what is or is not appropriate ways of acting in situations. What is learned, of course, are programed modules of social action. The use of "programming" denotes something else. The actions spawned by a program are not conditional or hypothetical they are deterministic. The "mental program", script, or mental model is a procedural instrument of action dependent on a recognized situation. And another model programs the mind to recognize the appropriate features of the situational environment.

Hofstede does not want to appear as deterministic as his words make him appear. A person's "mental programs" on the surface of action are flexible and adaptive as they construct "practices" which are variable socially. The deep structures of mental programs rest on collectively inculcated "values" which are deterministic of behaviors, i.e., practices [17]; [14].

So, a culture determines the value scheme, which frames all personal behavior. A person's "intellectual" and "emotional" machinery consists of the hard-core frames of values, which enforce identifiable perspectives evidenced in performances and language.

All this gives rise to the Hofstede Hypothesis. This is a perspective that no one can escape the bonds of the collectivity [12], the group and language, one was born into and raised in, and that one cannot escape the bonds of the society a particular group has lived-in; that "practices" may change, but "values" are permanent (but they are programmed as a source of the practices) [21]. As Hofstede et al. [13] write: "Not only organizations are culture bound; theories about organizations are equally culture bound".

Institutional frames such as professions and religion reflect a context and mindset that may be programmed to different cultural perspectives than prescribed by a national cultural average.

\section{The Hofstede Foundational Data in Perspective}

The conclusion that formed the basis of Hofstede's cultural profiles were based on Hofstede's 2 IBM studies with a combined data sample of 117,000 questionnaires. While the 2 studies involved 66 countries, only 40 of the countries yielded scores. As a result, less than one third of the 117,000 IBM employee responses were used in the study. Additionally, 6 out of the initial 66 countries yielded more than 1,000 survey results from the combined 2 studies. Less than 200 respondents were reported in 15 countries. The only surveys returned in Hong Kong, Taiwan and Singapore were 88, 71, and 58 respectively [20].

The actual questionnaires themselves were not designed to assess and identify attributes of a national culture but were designed by IBM as a tool to understand and analyze possible factors with respect to declining morale within the corporation. The questionnaires were not administered independently and without process. The completion of the questionnaires was not monitored for objectivity, integrity, and confidentiality. For instance, some questionnaires were not completed individually but rather in groups. Because of possible consequences and lack of confidentiality, the respondents answered subjectively, politically, and strategically. Finally, all workers were not represented; only marketing and sales staff — not blue collar workers [20]. In the initial studies - was the population survey representative of a national "average" profile or a skewed organizational and/or professional culture average?

While Hofstede acknowledges the data limitations and constraints, it appears that the national cultural profile implications, in essence, took on a life of their own. While the data may not be universally accurate, the study was both historic and important in that it was one of the first studies that provided a global corporate snapshot that was the basis for frame of analysis using generalizable observations. That is not to say that with refinement, cooperation, and design, Hofstede's questionnaire can be used in the focused context of respective professional, organizational, religious sub-cultures within the confines of a national label. 


\section{Flattening Factors}

While the Hofstede Hypothesis provided insight to understanding and harnessing cultural differences, its analytical impact has been and still is significant. Using his mode of analysis and questionnaire provides for a consistent cultural assessment tool. The resulting analytical frames (Hofstede's five-now six-dimensions), while regarded by some only as an interesting basis of discussion, can be used in the confines of more homogeneous cultures subcultures such as those discussed earlier to assess the overall validity of the Hofstede Hypothesis. Nevertheless, the model and the associated cultural profiles based on aggregate averages can be effectively used to analyze the possible impacts of phenomena like the internet, social media, the EU, the financial crisis of 2008 , and globalization on national cultural profile. Previous research has suggested that globalization, the internet, and social media have "flattened" the world as is evidenced by Hofstede cultural model compared values before and after the change variable had been mainstreamed [8]. More recent research has demonstrated that after the financial crisis of 2008, cultural profiles moved/returned closer to the values established by Hofstede [16]. The Hofstede Hypothesis and associated model and questionnaire can and should be applied to a segmented population based on a variety of demographic characteristics such as age, profession, ethnic identity, economic class, and education. The demographic segmentation can help answer questions such as the impact of social media on cultural identity and characteristics on 18 year olds versus 60 year olds. Is the profile the same? Does it change as one gets older to preestablished historical norms?

\section{Saudi Security Implications}

When the authors of the book Cultures and Organizations regarding how Saudis do business stated "for the Saudis, it's done with a person whom one has learned to know and trust." [13]. They were on the point. However, this trust is a value not only in business settings, Saudis do it in every aspect of their lives. For them, knowing someone make life easier. A look at the history of Saudi culture will revel a lot of how people in this culture think and operate. "As a political entity, the Kingdom of Saudi Arabia is a collection of families and diverse ethnic and religious groups which were united through conquest by 'Abd al-'Aziz ibn Sa'ud during the first quarter of the century." [10]. From there, Saudi Arabia was formed. The founder king Abdul-Aziz made sure that the leaders of the tribes swore an allegiance to him in exchange of power and money. Tribes in Saudi Arabia operate like their own small kingdoms. There is a leader of the tribe (who in Arabic is called Ameer) at the top of the pyramid, followed by advisors (usually the elders of the tribe and religious leaders of the tribe), and then comes the treasury and public relations and so on. Likewise, the families are like tribes in most ways but with a different terminology. For example, the leader of the family is called after a military rank, which is Brigadier-General (or Ameed in Arabic) of the family. His advisors are more educated the experienced (old); however, he is not the most powerful person in the family, but he is the most respected. "Tribal Leaders focus their efforts on building the tribe-or, more precisely, upgrading the tribal culture" [19]. The most important value the leaders of tribes and families in Saudi Arabia share is looking after their own people. "Tribes are one of the most influential factors in Arab life especially in the Arabian Peninsula. Reflecting their Bedouin heritage, a person's tribe offers protection from other hostile tribes or foreigners." [2]. Though, it's not only against hostile situations, they will come to help whomever is in need either a service or money.

In every form or shape, for the Saudi individual family or tribe comes first. "Family is a highly valued part of the Muslim society, and its significance can be perceived from high to non-educated people in all types of living; Bedouin, rural, and urban." [3]. This is what everyone in Saudi Arabia is taught since the beginning of his or her lives. There is a well known and widely quoted old proverb that Saudis live by and it says "Me and my brother against my cousin, and [but] me and my cousin against a stranger". This saying shows what can tribe's members are close and ready to help in time of need. "The programming starts within the family; it continues within the neighborhood, at school, in youth groups, at the workplace, and in the living community" [13]. However, in Saudi Arabia the person never leaves the family mentality behind and moves on, this mentality stay with in him or her through out all stages of their life. What this mentality does is creates the "connections" they need wherever they work either a government job or in the private sector. These "connections" have a nickname in the Saudi culture; the Saudis call it "vitamin C" (its vitamin WOW in Arabic due to the translation of "connections" in the Arabic jargon is Wasta). Having "vitamin C" gives the person power and ease of life. Meaning, the individual with a "connection" in a government agency can have his issues and needs done to him or her faster then the common person. For example, since all major universities in Saudi Arabia are public schools, knowing someone there or 
having "vitamin C" in one of these universities can secure a chair for the person even if they don't deserve it due to low-test scores or another reason; therefore, taking it from the people who worked hard and deserve it more. Another example, having a member of the family in the Department of Motor Vehicles (DMV) in Saudi Arabia means that the individual doesn't need to set foot in the department, everything will be done and made for him while he is in the comfort of his own home. There are many examples like these; however, the Saudi government became aware of this situation and how it effects the common man as well as the system, and when we say harming meaning people get privileges they don't deserve. They implemented a system that fixes this problem. It takes a lot of measures to insure equality between people. The system allowed everybody to register online to take an appointment for any government related needs. The upside here that no one from the inside can over ride the system and squeeze someone in, it must be done online. Moreover, the system will not give the individual an appointment to do anything else if this individual doesn't have their biometrics registered in government databases. Once they have their fingerprint registered, a person can finish all his government related issues online, and if they need to be present to collect or finish some paper work, the system will not allow going forward without a fingerprint identification. By implementing this system, "vitamin C" use is getting less needed since there is no point of it anymore.

Even though implementing a new system that minimizes "vitamin C" from being used that much, there are some ways around the system for a special group of people (let's call them the elite group). The elite group contains tribes and families related by marriage to a line to the throne member of the royal family, very high officials in the government like ministers and ambassadors, and very high ranked officers with high positions in the military sector. The elite group members get to have someone with a special permission to override the system to finish their needs. What this creates is that the common man starts to befriend these people to gain power over his peers in the tribe or family just from knowing a powerful person, and the closer this person the more power they get. For example, a minister can have a friend advisor with no knowledge in what the ministry do, but because he befriended the minister he has a job and he is the go to person in the family or tribe for help in any government issue. If we are viewing the Saudi culture as a social network that represent tribes and families as nodes in the network, the elite families and tribes will be the main nods that every other nod in the network connects to. However, the implementation of the e-government system reduced the size of the elite group compared to what it was before implementing the new system.

Being a family oriented culture, the sharing of information between an individual and a family member just because they are from the same family or tribe can be harmful to any organization. Employees are being careless in this case; they are just acting by nature. They are doing what the culture taught them their whole lives. If family is the most important thing in their lives, they will stay loyal to their families and tribe more than join their new tribe, which is the organization. "The key to this process is personal commitment, the employees' sense of identity with the enterprise and its mission." [22]. The biggest threat on information security these days is having the most important information in the incompetent hands. "Employees are often found to be careless and are often unaware of security directives, failing to comply with organizational information security policies and procedures. This may be caused by organizations possessing weak information security culture" [18]. This is due to the identity and loyalty to the tribe that is imbedded within the individual. Moreover, this loyalty can be really harmful and on a bigger scale when information is provided to the wrong people. Furthermore, the individuals that get this information can tweak it to their liking to make sure they get the most damage out of it. Terrorists, opposition politicians, and agitators all use information for the needs of their mission. For example, in Saudi Arabia an opposition activist doesn't need to be in the kingdom to get information, they only need people with cultural "connections" in sensitive parts in the government to believe in their movement and recruit them for information and use this information to make more people to believe in them and their message.

With the security aspect in mind, families and tribe will disassociate itself from a family member if this individual brought disgrace to the tribe's name. The most common way this can happen to a family member is by joining a terrorist group. The family or tribe will immediately will disassociate itself from this individual to not harm the family name and its position in the kingdom. One of the most famous disassociations that happened in Saudi Arabia is the Bin Laden family. The Bin Laden family is one of the wealthiest families in the kingdom with very strong connections with the royal family. However, when Osama formed a terrorist group named Al-Qaeda, the family disassociates from him and stopped any communications with him. "The ascetic Osama bin Laden could hardly be said to acclaim a ruler of the Kingdom for making his family, who has disassociated themselves from him, extravagantly rich." [25]. Nonetheless, people still thought that the family maintained type of connection with their 
family member in a way or another knowing his whereabouts and information about his plans. "Nevertheless, although probably not part of the $9 / 11$ plot, the family, their friends, employees, and staff may have had information that could have helped authorities identify and pursue those who did." [5].

\section{CONCLUSIONS AND FUTURE WORK}

Having a family oriented culture is not a bad thing by any means; however, the security threats that are coming out of sharing information that shouldn't be shared is what making this culture a bad environment to move information in. The most effective approach to a problem like that is trying to educate the public to the dangers of irresponsible sharing of information. Furthermore, train employees the importance of information security and have the right policies and procedures in place and guarantee compliance. Moreover, a closer look into the Saudi culture is needed to capture the relation between security and the culture, and how the impact from the Saudi culture harms information security.

\section{REFERENCES}

1. Abu-Musa, A. (2010). Information security governance in Saudi organizations: an empirical study. Information Management \& Computer Security, 18(4), 226-276.

2. ALArifi, A., Tootell, H., \& Hyland, P. (2012). Information Security Awareness in Saudi Arabia.

3. Aldraehim, M. S., Edwards, S. L., Watson, J., \& Chan, T. (2013). Cultural impact on e-service use in Saudi Arabia: The need for Service Oriented Culture.

4. Associates, J. (1992). Information security administration model: A management model to help identify the best practices of the administration function within the security group. Computers \& Security, 11(4), 327-340.

5. Brasch, W. M. (2005). America's unpatriotic acts: The federal government's violation of constitutional and civil rights: Peter Lang.

6. Chen, Y., Ramamurthy, K., \& Wen, K.-W. (2012). Organizations' Information Security Policy Compliance: Stick or Carrot Approach? Journal of Management Information Systems, 29(3), 157-188.

7. Davenport, T. H., \& Prusak, L. (1998). Working knowledge: How organizations manage what they know: Harvard Business Press.

8. DeLorenzo, G. J., Kohun, F. G., Burčik, V., Belanová, A., \& Skovira, R. J. (2009). A Data Driven Conceptual Analysis of Globalization-Cultural Affects and Hofstedian Organizational Frames: The Slovak Republic Example. Issues in Informing Science and Information Technology, 6, 461-470.

9. DiMaggio, P. (1997). Culture and cognition. Annual review of sociology, 263-287.

10. Doumato, E. A. (1992). Gender, monarchy, and national identity in Saudi Arabia. British Journal of Middle Eastern Studies, 19(1), 31-47.

11. Hofstede, G. (1983). The cultural relativity of organizational practices and theories. Journal of international business studies, 75-89.

12. Hofstede, G. (1993). Cultural constraints in management theories. The Academy of Management Executive, $7(1), 81-94$.

13. Hofstede, G., Hofstede, G. J., \& Minkov, M. (2010). Cultures and organisations-software of the mind: intercultural cooperation and its importance for survival (3rd ed.): McGraw-Hill New York, NY.

14. Javidan, M., House, R. J., Dorfman, P. W., Hanges, P. J., \& De Luque, M. S. (2006). Conceptualizing and measuring cultures and their consequences: a comparative review of GLOBE's and Hofstede's approaches. Journal of international business studies, 37(6), 897-914.

15. Kirkman, B. L., Lowe, K. B., \& Gibson, C. B. (2006). A quarter century of culture's consequences: A review of empirical research incorporating Hofstede's cultural values framework. Journal of international business studies, 37(3), 285-320.

16. Kohun, F. G., Burcik, V., \& Skovira, R. J. (2012). Research into Hofstede's Thesis. Paper presented at the Knowledge and Learning: Global Empowerment; Proceedings of the Management, Knowledge and Learning International Conference 2012.

17. Leung, K., Bhagat, R. S., Buchan, N. R., Erez, M., \& Gibson, C. B. (2005). Culture and international business: Recent advances and their implications for future research. Journal of international business studies, 36(4), 357-378. 
18. Lim, J. S., Ahmad, A., Chang, S., \& Maynard, S. (2010). Embedding information security culture emerging concerns and challenges.

19. Logan, D., King, J., \& Fischer-Wright, H. (2008). Tribal leadership: Collins.

20. McSweeny, Brendan. (2003).Is national culture a myth? A critique of the claims of Geert Hofstede. Research Seminar 12 November 2003 at School of Management, Royal Holloway, University of London.

21. Newman, K. L., \& Nollen, S. D. (1996). Culture and congruence: The fit between management practices and national culture. Journal of international business studies, 753-779.

22. Nonaka, I. (1991). The knowledge-creating company. Harvard business review, 69(6), 96-104.

23. Peltier, T. R. (2013). Information security fundamentals: CRC Press.

24. Usoro, A., \& Kuofie, M. H. (2006). Conceptualisation of cultural dimensions as a major influence on knowledge sharing. International Journal of Knowledge Management (IJKM), 2(2), 16-25.

25. Williams, M. S., \& Williams, P. (2008). The Weaponization of Oil in the Messages of Osama Bin Laden. Journal of Military and Strategic Studies, 10(2). 